\title{
Toward inclusive tech policy design: a method for underrepresented voices to strengthen tech policy documents
}

\author{
Meg Young $^{1}\left(\mathbb{D} \cdot\right.$ Lassana Magassa $^{1} \cdot$ Batya Friedman $^{1}$
}

Published online: 14 March 2019

(c) The Author(s) 2019

\begin{abstract}
To be successful, policy must anticipate a broad range of constituents. Yet, all too often, technology policy is written with primarily mainstream populations in mind. In this article, drawing on Value Sensitive Design and discount evaluation methods, we introduce a new method-Diverse Voices-for strengthening pre-publication technology policy documents from the perspective of underrepresented groups. Cost effective and high impact, the Diverse Voices method intervenes by soliciting input from "experiential" expert panels (i.e., members of a particular stakeholder group and/or those serving that group). We first describe the method. Then we report on two case studies demonstrating its use: one with a white paper on augmented reality technology with expert panels on people with disabilities, people who were formerly or currently incarcerated, and women; and the other with a strategy document on automated driving vehicle technologies with expert panels on youth, non-car drivers, and extremely low-income people. In both case studies, panels identified significant shortcomings in the pre-publication documents which, if addressed, would mitigate some of the disparate impact of the proposed policy recommendations on these particular stakeholder groups. Our discussion includes reflection on the method, evidence for its success, its limitations, and future directions.
\end{abstract}

Keywords Accountability $\cdot$ Design thinking $\cdot$ Experiential expert $\cdot$ Inequality $\cdot$ Inclusion $\cdot$ Methods $\cdot$ Policymaking $\cdot$ Technology policy $\cdot$ Underrepresented groups $\cdot$ Value sensitive design

\section{Introduction}

To be successful, technology policy must anticipate a broad range of constituents. Yet all too often, such policy is written with primarily mainstream populations in mind; those underrepresented may find themselves in a reactive position, unjustly treated. A case in point: the 1998 U.S. Digital Millennium Copyright Act (DMCA), which prohibits the circumvention of digital locks on hardware and software, also inadvertently prevents people who are blind and lowvision from adapting digital media for accessible use. Advocacy groups must petition for accessibility technology to

Meg Young

megyoung@uw.edu

Lassana Magassa

lmagassa@uw.edu

Batya Friedman

Batya@uw.edu

1 University of Washington Information School, Mary Gates Hall, Ste 370, Box 352840, Seattle, WA 98195-2840, USA be exempted from the DMCA's restrictions every 3 years (Richert 2016; Richert, n.d.). Or consider a second case from industry: in 2014, Facebook amended its "authentic identity" policy to require users to provide their "real" names, disabling accounts Facebook believed to violate the policy. These measures implicated users who had changed their names legally, such as members of the transgender community; use pseudonyms, such as political dissidents and domestic abuse survivors; or have names from religious and ethnic traditions (Haimson and Hoffmann 2016). More generally, two points are germane-had policymakers early on accounted for diverse groups, such unjust exclusion might have been avoided; and without substantive revision, the injustice continues.

Within the complex policymaking ecosystem, technology policy documents play an instrumental role (Sabatier and Weible 2014; Schlager 1995; Riker 1986). These documents, used to condense and synthesize information, often result from data collected via multiple channels and formats-spoken, image, text, and video. Ultimately these documents, culled by policymakers for insights and guidance 
on a particular policy issue, lay the foundation for policy analyses, solution generation, and eventually legislation.

To be clear, problems tied to unjust exclusion are not limited to tech policy; policymaking across a broad spectrum of societal activity has been similarly critiqued. While the source of such shortcomings is surely complex, questions of representation and inclusion remain central (c.f. National Urban Fellows 2012). Moreover, political representation for diverse groups is not simply a matter of legislator diversity. As Pitkin (1967) asserts, there can be critical differences between symbolic and substantive representation of a social or demographic group's interests and needs. In turn, scholars have highlighted the importance of dialogic, interactive methods to elicit public concerns about science and technology (Davison et al. 1997). Moreover, despite wide-ranging efforts to engage diverse citizenry, when the actual policy document is written, all too often perspectives from diverse groups are watered down or not incorporated (Kurath and Gisler 2009; Guston 1999).

It is within this socio-political climate with its corresponding issues of representation and inclusivity in the policy process that we bring design thinking to bear. Design thinking approaches make progress by envisioning alternatives to current conditions that, in both large and small ways, improve situations, circumstances, or experiences (Cross 1982; Nelson and Stolterman 2012). Rather than conducting comprehensive analyses of the type often associated with social-scientific approaches (e.g. Dryzek et al. 2009; Fung 2003), design thinking approaches can offer targeted insights about artifacts-in-progress that lead to improvement. In this work, we draw on value sensitive design to treat draft tech policy documents as artifacts to be designed and improved. The Diverse Voices method, which we developed in the United States context and contribute here, brings experiential experts more centrally into the tech policy document design process.

In this article, we first provide background on tech policy documents, inclusive tech policy, and design thinking approaches. Next, we describe the Diverse Voices method and present two case studies with emerging technologies that demonstrate use of the method with pre-publication draft tech policy documents. We conclude with reflections on the method, its effectiveness, limitations, and future directions. The Diverse Voices method contributes to inclusive tech policy by (1) changing the dynamic between experiential experts and their technical and policy counterparts in the tech policy arena, and (2) strengthening one critical aspect of the policy development process: namely, the tech policy document.

\section{Background}

\section{Tech policy documents}

Policy documents, including white papers and policy strategy, are authoritative, informative reports that provide an overview of a complex domain; they may advocate for a particular policy or regulatory solution (Herman 2013). Tech policy documents, in particular, acquaint policymakers with a given technology and its most salient aspects under existing law. The Diverse Voices method introduced here intervenes directly in the written instantiation of such documents at a critical late stage pre-publication juncture-that is, when a polished but not-yet-finalized tech policy document is ready for public comment.

\section{Inclusive tech policy}

Inclusive policy asks that "policy makers take as full account as possible of the impact the policy will have on different groups-families, businesses, ethnic minorities, older people, the disabled, women-who are affected by the policy" (Strategic Policy Making Team 1999, p. 44). There are many approaches to creating inclusive policy (Rowe and Frewer 2000; Abelson et al. 2003); each requires consideration of key stakeholders. Both early stage and late stage interventions hold promise for increasing the likelihood that impacts on affected groups would be anticipated and addressed in policies as they are developed. That said, many public engagement processes call for early stage, open-ended input; fewer offer methods for late stage elicitation on nearly-finished policy documents. While we support the need for engagement throughout the policymaking process, our approach targets this latter opportunity to make polished but not-yet-finalized policy documents answerable to those affected.

In developing inclusive tech policy, at least three kinds of experts are essential: technical experts comprised of technologists and scientists familiar with the technological capabilities and potential use cases of the technical innovation, policy experts comprised of policymakers familiar with pre-existing law and policy, and experiential experts comprised of diverse stakeholder groups whose lives will likely be substantively affected by the way a given technology will be instituted in society through policy. Specifically, we use the term experiential expert to refer to people who are living the experience or those closely associated with someone living the experience (e.g., family members, institutional advocates). In this regard, our approach shares affinities with feminist standpoint epistemology (Harding 1992; Hartsock 2003), in which the situated perspectives 
of marginalized groups offer privileged access to particular ways of knowing.

Historically, tech policy development has relied strongly on technical and policy expert-led approaches (Sturgis and Allum 2004; Wynne 2006; Frewer et al. 1998). Even in public engagement settings, technical experts exert authority in framing the debate, knowledge production, and decision making. Policy experts, in turn, garner political wherewithal and hold the pen on the written expression of policy and law. The specific language that makes its way into white papers and policy strategy wields enormous influence on what becomes law and regulation. From an inclusivity perspective, experiential experts have taken a backseat-particularly experiential experts from underrepresented groups. To mitigate this situation, we leverage this insight to intervene at the time of late stage policy document construction.

\section{Design thinking: value sensitive design and discount evaluation}

Design intervenes to generate better artifacts, situations, policies, or conditions within a given set of constraints. Nelson and Stolterman (2012) characterize design as a "third waydistinct from the arts and sciences... with its own approach to learning and inquiry," one concerned with "the ability to imagine that-which-does-not-yet-exist, to make it appear in concrete form as a new, purposeful addition to the real world" (p. 11-12). Cross (1982) describes design thinking as "designerly ways of knowing" (in contrast to scientific and other ways of knowing), Schön (1987) sees the designer's practice as reflective, and Coyne (2005) understands it as engagement with complex unpredictable problems in the world (what are called "wicked" problems). Van den Hoven et al. (2012) highlight the role of design in addressing complex moral challenges by expanding the feasible choice set. This, of course, only touches the surface of design thinking. To the above, we add value sensitive design, a particular approach for engaging with human values in the technical design process, and insights from discount evaluation. We bring both of these approaches to our work in the service of developing a method toward inclusive policy, in particular with respect to the refinement of tech policy documents.

Value sensitive design (VSD) is a principled and systematic approach to accounting for human values in the design of technology (Friedman et al. 2013; Friedman and Hendry in press). We drew on value sensitive design in numerous theoretical and practical ways. First, our overarching orientation to policy as a form of technology stems from VSD. From this perspective, a tech policy document is viewed as an artifact to be designed, albeit one that uses rules and regulations in lieu of wires and code to shape ways of being in the world. To date few studies have explored how VSD's theoretical constructs and methods could be employed in the design and development of tech policy. Here, we extend VSD to the design of tech policy documents as artifacts that instantiate policy directions.

VSD also calls on researchers and designers to consider both direct and indirect stakeholders. In conceptualizing "experiential experts" for the Diverse Voices method, we drew on this distinction, identifying those who directly interact with a technology and those who, while impacted by the technology, do so without touching the technology itself. This framing, particularly with its explicit attention to indirect stakeholders, broadens awareness of affected groups. Stakeholders may also speak from intersectional identities and may span multiple roles (e.g., in one moment a technology user, in another a bystander).

Further, we leveraged principles and heuristics from VSD to help prioritize stakeholder groups given limited resources (Borning et al. 2005). In making the hard decisions about which groups to include and which to set aside, many different types of ethical principles could be applied, such as utilitarian, deontic, or care ethics. Following VSD, our method does not prescribe a particular ethical theory, but rather asks for transparency about the rationale employed. Specifically, in our implementation of the Diverse Voices method we balance the magnitude of potential harm with barriers to representation, in order to prioritize panel groups which are likely to be significantly impacted and least likely to be represented in other feedback forums.

We also turned to VSD's empirical investigations for guidance on the content, structure, and techniques of panel facilitation (e.g., encouraging panelists to identify what is "broken," non-functional, missing, or mischaracterized in a current vision [e.g., white paper]) (Yoo et al. 2013). Finally, VSD invokes and legitimates approaches that result in "progress, not perfection" (Friedman and Hendry in press).

Turning now to insights from discount evaluation, early on we recognized that to be effective, any method we developed would need to be responsive to practical considerations, including being relatively quick to implement and low cost with respect to both the document author(s') and experiential experts' time. Discount usability methods operate within similar parameters (Nielsen 1994). We draw on both the structure and efficacy of one discount method-heuristic evaluation-sharing the following characteristics:

- Tech policy document author(s) (akin to a technology developer) provides the draft, unpublished artifact to be evaluated

- A small number of independent experts identify many, but not all, of the critical issues in a short period of time

- Facilitators prepare the draft artifact for review and synthesize recommended changes

- Author(s) receive synthesized feedback from which to make improvements 
- In the service of time and resources, the method gives ground on being comprehensive

Heuristic evaluation provides expert evaluators the opportunity to identify both problems and missing elements in a specific artifact. Importantly, the problems the experts find are not limited to the world-as-it-is, but also the world as-it-could-be.

\section{Related approaches}

We draw key lessons for our practice from previous work interrogating the assumptions underlying participatory approaches to policymaking. In particular, public participation methods-like citizen panels, citizen juries, consensus conferences, deliberative polling, and citizen advisory committees-are often presumed to be neutral tools for eliciting democratic engagement, yet, all too often, serve existing policy or institutional agendas (Voß and Amelung 2016; Irwin et al. 2013; Abelson et al. 2003). Organizers choose participants, who may not reflect the political, demographic, and socioeconomic diversity of the wider society (Irwin et al. 2013). Technical experts often dominate others in the discussion by framing the debate, deciding engagement procedures, using up discussion time, or by intending to "educate" lay participants rather than learn from them (Bickerstaff et al. 2010; Abelson et al. 2003). In this way, such efforts reify "one-way communication" and a power imbalance between experts and members of the public (Kerr et al. 2007; Abelson et al. 2003). When these methods are introduced late in the policymaking process, they may minimize the importance of public contribution (Abelson et al. 2003; Jasanoff 2003). Without strong ties to local context and community organizations, such efforts lose legitimacy (Voß and Amelung 2016).

The Diverse Voices method is not exempt from these challenges. That said, the method, structure, and facilitation style work to mitigate many of these concerns, particularly efforts to: (1) recruit experiential experts from diverse walks of life; (2) strive to make the technology and the tech policy document accessible; (3) instruct facilitators to withhold their own views; (4) create an environment that encourages panelists to provide their own perspectives; (5) invite panelists to introduce technology views and impacts that go beyond those considered in the document; (6) discourage panelist self-censorship; (7) provide panelists with the opportunity to give both verbal and written feedback; (8) provide panelists with the updated tech policy document prior to publication; and (9) invite panelists to critique the panel process. Taken together, these provisions actively respond to many of the current critiques of efforts to engage laypersons in the policymaking process (Bogner 2012).

\section{A new method: the diverse voices}

Developed in 2015 by the University of Washington Tech Policy Lab, the Diverse Voices method aims to identify substantive flaws in late-stage tech policy documents, while minimizing cost and time barriers to participation for experiential experts and authors. Here we describe the method. Details can be found in the How-to Guide (http:// techpolicylab.org/diversevoicesguide/).

\section{Identify the tech policy document}

A good candidate tech policy document is well developed (e.g., polished draft ready for public comment) and has author(s) amenable to making changes prior to publication. While the document may be presented to panelists "as is," in some cases, some changes to the document may be beneficial (e.g., removing technical footnotes). Design research demonstrates that artifacts that appear less finished are more likely to elicit critique than those that look complete (Rettig 1994); facilitators may provide documents in a drafty-looking format to be more conducive to input. Consideration of factors such as panelists' literacy or age may support additional changes.

\section{Role of facilitators}

Facilitators participate in selecting the tech policy document, identify and select stakeholder groups, recruit panelists, lead and moderate panel sessions, analyze and synthesize panel recommendations, and communicate recommendations to the document's author(s). We recommend panels be moderated by two facilitators. Once a document has been selected and prepared, running a Diverse Voices panel requires an estimated 40-h per facilitator, with the bulk of that time for recruitment and synthesis.

\section{Select stakeholder groups}

The next phase entails identifying the stakeholder groups for panels. First, facilitators generate a list of direct and indirect stakeholders, casting a reasonably wide net. To this end, facilitators may envision likely scenarios for how the technology will be used over time, and its potential impacts on law and society. Then, given resource constraints, facilitators narrow these to a small subset of stakeholder groups by employing a variety of principles (e.g., prioritizing groups with anticipated significant impacts who likely would not otherwise have formal representation in the policymaking process; see "Design thinking: value sensitive design and discount evaluation"). We recommend 
convening at least three groups to ensure some range of perspective.

\section{Convene panels}

Then turn to recruiting experiential experts to speak to the perspectives of each stakeholder group. Each panel meeting is held separately. We engage experiential experts from two vantage points: those who live the experience, and those who are closely associated with those living the experience (e.g., family members, institutional advocates). Note that while some policy engagement methods conflate lived experience with "laypersons," we look to lived experience as a form of expertise. Panels have a minimum of three participants (at least one of whom has lived experience) and are internally diverse (e.g., age, background). Facilitators recruit members of the community to serve as panel experts. Care should especially be taken with communities that may have stigma attached to their status. In these instances, community organizations can play a helpful role in connecting facilitators with their constituents. At least 2 weeks before the panel is convened, panelists are provided with a copy of the draft tech policy document to read and review.

\section{Pre-panel preparation}

Facilitators identify video clips and magazine cartoons that demonstrate the technology's functionality and its potential use in everyday or near-future scenarios. These clips and cartoons will be used to help the panel consider the technology's downstream implications and the policies governing it. While the multimedia examples presented influence the panel conversation, in our experience they do not limit the conversation's scope. Rather, respondents interpolate the featured technology into their everyday lives.

\section{Running a panel}

Panels comprise a 90-min roundtable discussion. Facilitators begin by asking panelists to introduce themselves and their connection to the stakeholder group. Facilitators remind panelists the goal is to refine the exact language used in the tech policy document which, when published, will be circulated to policymakers. Then, facilitators use video clips and cartoons to introduce the technology featured in the document. This activity creates an entry point for panelists to participate regardless of previous familiarity with the technology, sets a relaxed tone, and establishes a shared critical frame for the discussion.

Next facilitators ask panelists for their first impressions, eliciting their sense of the broader implications of the technology for the stakeholder group. For example, facilitators might ask, "How might the use of this technology be concerning/hopeful for [the stakeholder group]?" Open discussion allows panelists to engage on the terms they believe are important.

The bulk of the panel (about 60-min) solicits targeted comments on the substance of the draft document, with particular attention to content that may have disparate impact on the stakeholder group. Considering each section of the document, facilitators invite panelists to speak to aspects they deem important. For example, facilitators might ask, "What mistakes could policymakers make because of how this document is currently worded?" "What does the document not say that you wish it said?" "What is not working in this document?"

\section{Analyze and synthesize panel results}

To be useful to the document's author(s), the panelists' comments are synthesized and connected to the document in a way that positions the author(s) to make improvements. The "work" of synthesis and connection falls to the facilitators. Analysis and synthesis are conducted within, but not across, panels.

\section{Thematic analysis}

Drawing on qualitative coding practices, the thematic analysis begins with the verbatim panel transcript. Facilitators identify transcript segments where panelists provide input on the document. For example, "This [policy] was very punitive, and it wasn't incentive based." Next, facilitators cluster and label closely-related quotes with a phrase capturing the main idea. For example, the quote above, combined with others might be labelled "Punitive strategies." Then facilitators group related clusters and generate higher-level themes. For example, "The legal strategies recommended by the author will have a disparate impact on extremely lowincome people." The final outcome entails a summary of panelist feedback via higher-level themes that are comprised of descriptive labels and supporting quotes.

\section{Synthesis}

Next, key insights identified in any level of the thematic analysis are connected to specific text in the document. The final result is a memo addressed to the author(s). Each insight contains a title, summary, supporting panelist quotes, and page numbers for relevant passages in the document.

\section{Post-panel interaction with panelists}

When the author has finalized the tech policy document, the final version is shared with panel participants. We do so for two reasons. First, so that panelists can see the direct impact 
of their comments on the final document. Second, so that if panelists feel there are still inadequately addressed concerns, they have an opportunity to inform the Diverse Voices facilitators who, in turn, convey that information to the author.

\section{Case study I: augmented reality}

We turn now to the use of the Diverse Voices method with a white paper on augmented reality (AR).

\section{Augmented reality white paper}

Authored by our colleagues at the UW Tech Policy Lab, the white paper "Augmented Reality: A Technology and Policy Primer" represents a collaboration among computer scientists, legal scholars, and information scientists. The document presents examples of potential applications, an in-depth technical overview, and key legal and policy issues; little is provided in the way of specific policy recommendations. Length: 20-pages. Readability Grade Level: 11.6 (Flesch-Kincaid).

\section{Technology overview: augmented reality}

AR technology entails overlaying digital information onto the physical environment. AR systems typically sense the physical world, process and output data in real-time, provide contextual information, and recognize physical objects in the world. To introduce AR to panel participants, facilitators showed publicly available video clips to convey how it might be used in society.

\section{Select stakeholder groups: people with disabilities, currently and formerly incarcerated, and women}

In our first effort with the Diverse Voices method, our process for identifying potential stakeholder groups was truncated. Specifically, we focused on groups who typically are not well represented in the tech policy process: people with disabilities, based on the potential for AR to help lowvision users navigate their surroundings; currently or formerly incarcerated people, based on public stigma attached to people with a criminal history; and women, based on a belief that women may feel exposed in public space.

As shown in Table 1, panels were comprised of experiential experts with both lived experience and institutional expertise. Time to recruit panelists varied by community: people with disabilities $(20 \mathrm{~h})$, currently and formerly incarcerated $(50 \mathrm{~h})$, and women $(30 \mathrm{~h})$. On average, panelists spent $6 \mathrm{~h}$ preparing for and participating in the panels. Panelists were not compensated for their time.
Table 1 Number of panelists per panel, by type of expertise

\begin{tabular}{llll}
\hline Panel & $\begin{array}{l}\text { Lived the } \\
\text { experience }\end{array}$ & $\begin{array}{l}\text { Associated } \\
\text { with group }\end{array}$ & Total panelists \\
\hline $\begin{array}{l}\text { People with disabilities } \\
\begin{array}{l}\text { Currently/formerly } \\
\text { incarcerated people }\end{array}\end{array}$ & 1 & 2 & 3 \\
\begin{tabular}{l} 
Women \\
\hline
\end{tabular} & 3 & 2 & 3 \\
\hline
\end{tabular}

Asterisk indicates participants who are members of both groups (e.g. a woman who works for a woman's organization)

In the sections that follow, we present some key insights garnered from each panel. Space precludes a more comprehensive presentation of panel results.

\section{People with disabilities panel}

\section{Panelists}

Panelists were recruited from universities and institutions devoted to serving people with accessibility needs. One panelist was blind; this panelist also developed assistive technology and advocates for vision-impaired people. A second panelist was raised in a family where both parents were deaf; this panelist was also a researcher who develops new technologies for people with disabilities and advocates for individuals with disabilities to enter the computing field. A third panelist worked on local technology and accessibility issues.

\section{Insights}

Perhaps the most crucial piece of feedback from the panel on people with disabilities pertains to the white paper's definition of AR. Panelists took issue with one aspect of the way AR is typically defined in the technical community, namely that AR entails "output (overlay) information to the user. Information gathered and processed by the system will generally be overlaid on the user's usual perception of the world" (p. 6). Experiential expert panelists critiqued this definition, pointing out that a blind or low-vision person could experience AR not simply as "augmenting" an existing sense, but replacing it. For example, an AR headset with spatial recognition could help a blind or low-vision user to navigate physical space by providing audio cues-in effect, shifting sense modalities from visual to aural. A panelist recommended amending the definition to reflect the use of AR as a sense modality - a more nuanced and inclusive definition of AR. In this way (and in contrast to previous approaches to policy engagement processes in which the policy framing seems to determine the scope of the conversation), the Diverse Voices method takes the draft policy document as a starting point, and looks to panels to find problems with the established frame. 
How AR is defined matters; at stake is the scope and boundaries of regulation. The original definition of AR as additive positions it as akin to a luxury item, the use of which could be constrained to accommodate other concerns. Under this conception, governments could, for example, conditionally ban AR in certain settings to preserve privacy; unintentionally, such policy could harm those who have come to depend upon the technology. As one of the experiential experts said, "You know, you walk into a bathroom it automatically has to shut off or something. But if somebody with low vision is using it to navigate in the space then you wouldn't want that to happen." Importantly, defining AR as replacing a sense could protect users from this possibility by laying the groundwork for considering AR to be an assistive technology with entitlements under laws such as the Americans with Disabilities Act.

\section{Currently and formerly incarcerated people panel}

\section{Panelists}

Panelists were recruited from community-based reentry programs, legal defense institutions, and prisons. One panelist worked as an advocate for incarcerated fathers, and selfidentified as having been addicted to drugs and in prison earlier in his life. A second panelist taught courses in state prison including bookkeeping, anger management, and job seeking skills; her parent had been imprisoned. A third panelist was a lawyer who helps people in prison with family law and child welfare issues.

\section{Insights}

Panelists asserted that policies that do not encourage thoughtful consideration of AR use will generate mistrust between law enforcement and communities, and could create a situation where low-income and minority communities are surveilled at a disproportionately higher rate than others. One panelist commented, "My immediate sense is, like, how this would be taken by either police stations or people in those agencies that are quote unquote 'supposed to protect us?" This comment alludes to the idea that punishment, particularly for the formerly incarcerated, would extend beyond the prison walls. Police might use an AR tool to bring up background checks of those within view of the device's camera.

Panelists broadened the vision for AR systems in the lives of incarcerated people. They provided a scenario highlighting the potential for AR to enhance education: "[It could] provide education in the prison system and provide like experiences that folks aren't able to have. And as long as we are gonna lock people away, like having more access, I guess, and if a professor is able to like tune-in via the hologram type of thing, HoloLenses... I know it makes [me] think of like MIT... online education." In this example, we see that the audiovisual examples of technology used at the beginning of the session did not over-determine the scope of the conversation. Rather, the panelists were invited, through a series of open questions to take up the technology and bring it into their own experiences. The resulting discussion is generative of new scenarios that the tech policy document authors did not anticipate.

\section{Women panel}

\section{Panelists}

Panelists were recruited from community organizations focused on women and in companies started or led by women. One panelist was a scientist. A second panelist directed an organization advocating for girls to learn technology skills. A third panelist worked for a technology startup.

\section{Insights}

The women panel emphasized that AR has the potential to empower women to carry out certain activities that they might otherwise view as difficult. One panelist said, "[It] could also be immensely empowering to women who then feel like, I can go somewhere, I can be hands free, I can be more confident. I don't have to look like I don't know what I'm doing because I'm always staring down at my phone following the map." Here, the panelist suggests that because AR allows users to be more aware in public space, it could make women feel more secure. Of note, the original version of the white paper stated that AR may cause bystanders in a public space to feel surveilled. As facilitators, we shared this concern; we had also assumed based on prior research that some women would feel uncomfortable being watched in public space. Instead, panelists embraced AR as helping them to feel more secure. Importantly, panelists were able to disagree with both the authors of the policy document and the facilitators.

The women panel also discussed how AR devices could contribute to an environment of stronger accountability. Panelists suggested that the covert nature of AR makes it a potentially useful tool to document cases of abuse, whether physical, verbal, or otherwise. The panel emphasized that policies should be written in a way that prevents law enforcement and legal professionals from circumventing or discrediting information captured by AR devices. 


\section{Author reflections}

Thematic analyses and synthesis from each of the three expert panels were provided to the white paper authors. Following publication of the white paper, we contacted lead author Ryan Calo to understand whether the expert panel comments were useful in revising the white paper. Calo reported that the Diverse Voices process had a substantive impact on revisions to the white paper.

\section{Definition of AR}

The authors revised their definition of AR in response to panelist feedback: "We changed the definition of augmented reality, ... we had been defining it as adding a layer of information on top of reality, and adding to the senses, but we re-conceived it based on the disability conversation as adding to or substituting for missing senses." The revised white paper reflects that AR can replace a sense—not just augment an existing one.

\section{Impact on stakeholder groups}

The authors also reconsidered the way they portrayed the potential impact AR technology could have on certain stakeholder groups. For example, with regard to women, the authors balanced the concern that AR could further compromise women's privacy with the recognition that these same tools could also increase women's sense of security.

\section{More powerful use scenarios}

The authors built on the panelists' suggestions to broaden envisioned use cases in the revised white paper. The author said, "For me, the one that jumps out is the use [of AR] in prisons... Our example was going to be teaching Stanford quarterbacks how to pick receivers, and instead we got much more powerful examples."

\section{Salience of race}

Calo reflected on the emergence of a popular AR-based game released after the white paper was published, Pokémon Go. He noted that the white paper did not anticipate a problem presented by the game - that many young men of color were not comfortable using the game because "the actual instantiation of augmented reality in that instance requires you to go to places you're not used to going, possibly at night, holding something in front of your face and pointing it around... Understandably there have been op-eds that ... said that they wouldn't use Pokémon Go. We didn't anticipate that. Notwithstanding the fact that we ran the panels through a diverse group of folks." Calo suggested that a panel on race should be run every time the method is used:

One of the lessons, I think... is that there might be aspects of society that so chronically or pervasively present an issue that we might consider always running a panel on it—one of those might be race. In our society, race is one of the pervasive touchpoints and many, many things, when they get deployed, wind up having racial dynamics.

\section{Post panel interaction with panelists}

As described above, the authors modified their white paper on AR as a result of the synthesized feedback received from the Diverse Voices facilitators. Prior to publication, this revised white paper was shared with panelists so they could see the impact of their contributions on the document. Panelists were also invited to contact the Diverse Voices team if there were outstanding issues that they felt had not been adequately addressed. None expressed concerns about the revised document.

\section{Case study II: automated driving vehicles}

In our second case, we refined the Diverse Voices method with a strategy document on automated driving vehicles (ADV).

\section{Automated driving vehicles paper}

Written by law professor Bryant Walker Smith at the University of South Carolina, the tech policy strategy document, "How Governments Can Promote Automated Driving," presents administrative, legal, and community strategies available to any government that would like to encourage automated driving. Length: 46-pages. Readability Grade Level: 13.8 (FleschKincaid).

\section{Technology overview: automated driving vehicles}

ADV refers to computer systems that use sensors and assist drivers with particular tasks without active intervention. While popularly referred to as "driverless cars," ADV systems fall along a spectrum of functionality-from those commonly available in new cars today (e.g., assisted parallel parking) to full automation (e.g., independent operation of vehicles in real-world conditions). To introduce panelists to ADV, facilitators showed three video clips followed by four New Yorker-style cartoons. 


\section{Selecting stakeholder groups: youth, non-car users, and extremely low-income people}

To identify panels, we cast a wide net of potentially salient stakeholders for ADV, including extremely low-income people, fleet drivers, people living in rural areas, people with disabilities, non-car drivers, senior citizens, and youth. Narrowing to three, we selected: youth, based on a sense that ADV would afford them increased autonomy; non-car drivers, based on a sense that ADV might raise safety concerns; and extremely low-income people, based on our unresolved questions around who would benefit from ADV. Drawing on the principle to prioritize groups unlikely to have formal representation, we did not select senior citizens or fleet drivers as we considered them to be reasonably well represented by advocacy groups.

As shown in Table 2, panels were comprised of both types of experiential experts. Time to recruit panelists was approximately 20 -h per stakeholder group. Each panelist was compensated $\$ 150$.

\section{Youth panel}

\section{Panelists}

Panelists for the youth panel were recruited from a county youth development program, a local technology access youth organization, and local arts organizations. One panelist was a 16-year-old young woman involved in state politics. A second panelist was an educator who had worked most of his career directly with youth, but recently began working with educators who serve at-risk youth. A third panelist was a parent who works for a foundation that promotes public education, in a role advocating for underrepresented youth in STEM fields.

\section{Insight}

Privacy implications for youth were of concern to panelists. While the strategy document engaged potential privacy implications of ADV data recorders for adults, panelists

Table 2 Number of panelists per panel, by type of expertise

\begin{tabular}{llll}
\hline Panel & $\begin{array}{l}\text { Lived the expe- } \\
\text { rience }\end{array}$ & $\begin{array}{l}\text { Associated with } \\
\text { group }\end{array}$ & $\begin{array}{l}\text { Total } \\
\text { pan- } \\
\text { elists }\end{array}$ \\
\hline Youth & 1 & $3^{*}$ & 3 \\
Non-car drivers & 2 & 1 & 3 \\
$\begin{array}{l}\text { Extremely low- } \\
\text { income people }\end{array}$ & 2 & 2 & 4 \\
\hline
\end{tabular}

*Indicates participants who both lived the experience and were associated with the group thought the at times impulsive behavior of youth coupled with the large amount of personal data captured by ADVs could overly expose youth to parents and law enforcement. As one panelist said:

Between Facebook and social media so much of those experimental ages where discretion isn't the norm, I just worry about, at a data level, how much more of students' lives and youth's lives are going to become the subject of public inquiry or private inquiry for that matter-[their] affiliations, networks, things of that nature.

According to panelists, the situation is compounded for at-risk youth for whom consequences of indiscretions are already less leniently applied.

Panelists raised provocative questions about how the law governing ADVs would need to be adapted when all the passengers are minors; "That opens up this whole other policy question about liability and all of that stuff." Another panelist added, "Who would be held responsible? Especially if there were children in the car-if there was no adult in the car." Who is liable and who is accountable in the event that the minors are harmed or cause harm?

\section{Non-car drivers' panel}

\section{Panelists}

Panelists-all self-identified non-car drivers-were recruited from bicycle shops, bus stops, and local commuter advocacy organizations. One panelist had not owned a car for 8 years and used his bicycle for transportation. A second panelist had recently moved to the United States and never owned a vehicle; he used public transit and a bicycle. A third panelist walked or used public transit and rideshare services since selling her car 10 years previously; she works for an advocacy organization focused on affordable public transit.

\section{Insights}

As non-car drivers, safety was important. That said, panelists differed in their beliefs as to whether or not (and how) ADVs might affect safety for nondrivers. One panelist feared greater vulnerability when walking or bicycling. Another panelist thought otherwise: "I walk to work every day and not a week goes by where I feel like I don't almost get killed. If I knew that every car was autonomous and was not going to make that mistake, maybe I would get more excited about them." Critical to these comments is the need for accurate information about the actual performance of ADVs in real world driving conditions.

Panelists felt the strategy document took for granted that governments should promote ADVs, without providing 
rationale or identifying widespread benefits beyond economic ones. One panelist said, "If you never want to be in a car, how does this technology help you or not help you? I think, again, there's a lot of presumption ..." Other panelists suggested expanding the document's scope to consider potential environmental impacts. For example, one panelist envisioned ADVs could change car ownership, leading to more efficient transportation, while another pointed to potential benefits for land use.

\section{Extremely low-income people panel}

\section{Panelists}

Panelists were recruited from a local organization that provides housing and job training for people released from prison or jail, recovering from addiction, and experiencing homelessness. The organization hosted the panel for the convenient access of participants. One panelist was the organization's vice president. A second panelist self-identified as extremely low-income; due to a previous felony, she has had difficulty finding a job and stays at home with two young children. A third panelist self-identified as someone who grew up in an extremely low-income household and was currently experiencing financial challenges. A fourth panelist ran an organization that provides bathroom, shower, laundry, and other services to homeless people at no cost.

\section{Insights}

Panelists identified ways that the recommendations in the strategy document would have disparate impact on extremely low-income people. The document suggested several legal strategies to incentivize adoption of ADV, many of which relied on tighter enforcement of existing laws; these included raising fuel taxes, reducing parking subsidies, enforcing laws on car emissions in older vehicles, and mandating higher insurance minimums as strategies to promote driverless car adoption. One panelist said, "It [the legal strategies section] was very punitive, and it felt like, "we will make your life miserable until you decide to do this." The panelists also responded to the document's recommendation that existing law should be more carefully enforced. Based on their experiences, panelists were concerned that low-income people are more likely to be put in a position to violate laws with which they could not afford to comply.

I had the sense... that it could be kind of selective enforcement, that it would come down heavier on people with cars that weren't automated, and it's kind of ludicrous. I mean I had a beater car some 40 years ago, and I couldn't afford the money for a muffler, so I got tagged for that because it made some noise. I went down to the court. The court asked me, 'Well, how come you can't buy a muffler?... you buy gas.' I said, 'Yeah, 2 bucks a gallon,' so I managed to get off on that one, but ...I was a sitting target because of economics. This is what you're going to get people-just on the basis of economics on their vehicle?

Panelists emphasized the value of personally-owned cars for families as opposed to shared vehicles. The panelist pointed out that car ownership is more cost-efficient for extremely low-income families:

This paper is stating that we should eliminate [parking spaces] so that you don't have anywhere to park your car. Therefore, you'll want a driverless car, which to me says, wait, so I'm not owning a vehicle at all. I'm just paying for a taxi then to come pick me up all the time ... I've got two small kids. I used to ride the bus all the time. I cannot take a 2-year-old and an infant on a bus and go grocery shopping. I physically cannot. I can't. So if this was the rule, I' $m$ going to have an unregistered, uninsured vehicle, and I'm going to do it that way.

Here, the experiential expert strikingly brings the proposed policy to bear on everyday life, and remarks that in the face of recommended policies, extremely low-income people would be likely to forgo vehicle insurance and registration entirely. While the draft document had acknowledged this possibility, it had not considered the social and political dimensions of making access to transportation more difficult for extremely low-income people.

Panelists noted that the question of how the technology could become available to poor people was largely unaddressed in the strategy document. The document mentions that driverless car technology could be used as part of transit systems, but does not fully develop this idea and its feasibility as a public spending project. Furthermore, panelists expressed some skepticism that automated driving cars are well-suited for these purposes; they noted that human drivers in buses and accessibility vans play a crucial role in assisting elderly and disabled people as they enter and exit a bus or van. They also found that the primary beneficiaries of driverless transit investment would be private companies.

\section{Author reflections}

As with the AR white paper, thematic analyses and syntheses from each of the three expert panels were provided to the document's author, Bryant Walker Smith. Smith said that the panelist mechanism was valuable in his work; "Your Diverse Voices program both (1) makes me more sensitive to [others'] perspectives, and (2) could offer a mechanism for me and others to much more meaningfully engage with the relevant 
communities on these kinds of questions." He reported that the time commitment to participate in the process "made it really easy on [him]." He also appreciated the memo format that clarified who the panel represented and provided supporting quotes. In some cases, he would have been interested in seeing more context situating a particular quote.

\section{Maintaining policy recommendations}

Smith was struck by but appreciative of the tone of some of the comments by some of the extreme low-income panelists. He agreed with (and in his draft document had acknowledged) the substance of the critique-that some of the policies he advocated could in some ways negatively impact some extremely low-income people in the near term. He also defended those policies:

Nonetheless, driving imposes costs, and those costs are not reflected in the price of driving or vehicle ownership, and that has negative consequences-including on safety.... I anticipated the pushback, and in some ways agree with the larger frustrations, but nonetheless will continue to recommend ... that driving is too cheap. At the same time, support services and transportation options are far too neglected... Those are two truths, and I do acknowledge the [latter] in the paper, but I'm dealing primarily with the [former].

\section{Understanding broader audiences' reactions}

At times, the Diverse Voices process produced discussion that the author felt was outside the scope envisioned for the document. The author said:

[There was] tension in the comments ... between a broader audience $\ldots$ of interested people or stakeholders ... versus the audience that I was writing for. For example, are automated vehicles good? Well, that is a topic of tremendous discussion and tremendous importance. It is unequivocally and explicitly not something I address in my paper... Those are the areas where I wouldn't change the content in response to comments.

This case illustrates that a difference can arise between the scope intended by the author and what the panelists found to be in-scope in their discussion. As a result of this gap, several insights did not make it into the revised policy document.

\section{Post-panel interactions with panelists}

In the case of the ADV paper, the author did not modify the tech policy strategy document. As a result, panelists received no further correspondence about the ADV document.

\section{Discussion}

Presumably uncontroversial, effective technology policy meaningfully accounts for the lived experiences of the people whose lives are impacted by it. Yet how to achieve such inclusive policy remains elusive, especially so when a wide range of diverse stakeholder groups are affected. We believe a design thinking approach with a co-constructive orientation and emphasis on making improvements (without aiming for "perfect" solutions) may offer a constructive way forward. Toward addressing this gap in practical know-how, we contribute the Diverse Voices method. Intervening at the pre-publication phase of tech policy document development, the Diverse Voices method employs a design thinking approach to help surface substantive limitations in the document where meaningful improvements could be made. The hope is that by making these limitations known to the author(s) prior to publication, revisions could be made before policy is written and implemented.

We begin this discussion with the question: how well did the Diverse Voices method work? Then we reflect on design tradeoffs and limitations of the method, and finally point to fruitful directions for future work.

\section{Assessing the Diverse Voices method: evidence from the case studies}

Previous approaches to public engagement in policymaking have been characterized at times as symbolic exercises of input at the expense of meaningful change (Bickerstaff et al. 2010; Abelson et al. 2003), as one-way communication from experts to laypeople (Kerr et al. 2007; Abelson et al. 2003), and as occurring too early in the policymaking process to measurably change outcomes. Instead of convening experts and laypeople on uneven terrain as in the deficit model of public understanding, the Diverse Voices method re-centers public engagement around input derived from firsthand experience. The impact of this input can be measured directly in the degree to which policy documents are changed in response to panel remarks.

The Diverse Voices method succeeds if it positively impacts the quality of a tech policy document from the perspective of diverse constituents and does so in a resource efficient manner. To be impactful, three things must happen. First, the method must provide an environment in which underrepresented groups are able to speak honestly about the proposed policy implications in a document, even when their views run counter to the framing and normative assumptions of the policy author and/or facilitators. Second, the method must help to surface some 
substantive insights that point to places in the document where critical improvements could be made. Third, the document author(s) must act on as least some of these insights - that is, the insights must be presented in such a way that they are compelling and actionable to author(s).

In terms of providing access and an environment that encourages honest and meaningful voice, evidence from the two case studies indicates success. For example, people from a wide range of stakeholder groups-people with disabilities, youth, women, currently and formerly incarcerated people and extremely low-income people-were willing to provide scenarios of use and other policy implications that were not anticipated by the policy authors. At certain times, their input diverged from authors' assumptions. Some participants were more forthcoming than others; to stimulate participation, participants were periodically reminded that the facilitators were interested in hearing about the shortcomings of the document. On balance, they found the technology and policy implications as presented through the tech policy document itself and the supporting videos and cartoons accessible, as demonstrated by their ability to comment on the document and to suggest alternative scenarios, potential disparate impacts, and so forth. They also found the panel environment reasonably safe for speaking openly as evidenced by their humor, story-telling, and open critique.

In terms of surfacing substantive insights, evidence from the two case studies also indicates success. For example, for AR technology (Case Study 1), the people with disabilities panel challenged the initial technical definition of AR-illustrating how that definition did not account for their experience (e.g., replacing one sense with another) and demonstrating how AR technology could qualify as an assistive technology. Similarly, for ADV technology (Case Study 2), the extremely low-income panel emphasized that some of the recommended legal and policy strategies would result in a disproportionate burden on people in poor communities.

However, in terms of author uptake, the results were mixed. To the positive, authors in both case studies agreed that the insights for their respective papers were substantive, pointing to important limitations or missed opportunities. Importantly for our assessment purposes, the author for the AR white paper made significant changes based on the panel insights. In contrast, the author for the ADV strategy document made few, if any, changes, seeing the suggestions as beyond the scope of the document. That said, this author found that the Diverse Voices process had enhanced his perspective and will influence how he approaches future tech policy documents.

For authors, the method requires minimal costs-the author supplied the pre-publication tech policy document and received synthesized comments in return. As appropriate, authors also needed additional time to revise the document in light of feedback. For panelists, the costs are also relatively minimal - an investment was made of $6 \mathrm{~h}$ on average per participant to read the tech policy document in advance and then the time to attend the panel. The burden of coordinating, organizing, facilitating, and synthesizing results falls to the facilitators. On average, each panel required about $40 \mathrm{~h}$ per facilitator $(80 \mathrm{~h}$ total facilitator time). While the amount of time is significant, it does not seem out of line with other more deliberative, upstream processes that require more significant time investment from the other participants. Moreover, as facilitators gain experience with the method, develop relationships with stakeholder communities, and so forth, we anticipate the facilitator time would decrease.

In sum, from the perspectives of impact and resource effectiveness, we conclude that the Diverse Voices method contributes on balance a resource-effective means for eliciting meaningful stakeholder insights.

\section{Reflections on the method: design tradeoff or limitation?}

From the perspective of participatory democracy, the Diverse Voices method poses several puzzles. Recall that the Diverse Voices method succeeds, in part, because it leverages the insights of a few to identify critical areas for improvement and does so in a way respectful of the time and resources of both experiential experts and document authors. In this respect we think the method is well positioned. That said, issues of representativeness, scope of engagement, and sustained engagement warrant reflection.

\section{Representativeness}

The Diverse Voices method employs a panel of three to six experiential experts to surface potential negative impacts and alternative use cases pertinent to a given underrepresented group. The method does not claim to represent all the individuals who identify as members of that group nor even to surface all the issues for that group. The risk of working with such a small number of experiential experts is that their insights are not fully reflective of the larger community. Larger panels would go some distance to mitigate this concern, but at the expense of individual panelist engagement. Retaining the panel size and conducting additional panels with the same unrepresented group would also go a distance to mitigate this concern, but at additional expense. Further research is needed to explore what an optimal panel size might be and how many panels from a particular underrepresented group are required before saturation of insights are reached. But the constraints of resources remain. 


\section{Scope of engagement}

Another concern entails the scope of facilitator decisionmaking. In the current formulation of the Diverse Voices method facilitators make most key decisions, including which underrepresented groups to convene as panels; which multimedia artifacts to use to introduce the technology to panelists; where to hold panels; and what themes, insights, and recommendations to include in the synthesized comments provided back to authors. These decisions risk facilitator bias or blind spots. For example, when synthesizing panel transcripts, facilitators may unwittingly misinterpret and miscommunicate the ideas of experiential experts. Bringing panelists into the panel analysis and synthesis process would go some distance to mitigate this concern, but with an additional time commitment and learning curve from panelists. Similar approaches could be taken for other facilitator decisions, increasing experiential expert empowerment. How to balance scope of engagement and, relatedly, empowerment with the burden to participate remains an open question.

\section{Sustained engagement}

The Diverse Voices method is a step above one-way communication from technical and policy experts to laypeople, in that experiential experts have the opportunity to provide substantive comments to tech policy document authors. This occurs at two points: first, when facilitators provide authors with a comprehensive synthesis of input from a single 90-min panel discussion and, second, when panelists individually review the revised document (assuming revisions were made). That said, the current formulation of the Diverse Voices method does not facilitate direct or on-going conversation between underrepresented communities and authors. The risks here are manifold. A single 90-min discussion may not be adequate for surfacing most or all of the panelists' key concerns. Perhaps the written synthesis does not convey the strength of panelists' feelings and fears. Or, the author could have follow-up questions that are critical for understanding concerns and how they might be addressed. Indeed, panelists could prefer a stronger form of accountability that their concerns have been heard and taken into account. On the other hand, panelists may feel freer to express their concerns if they do not interact directly with the author. In addition, increased requirements in terms of time, commitment, or depth of on-going engagement may themselves become barriers to participation. Striking a workable balance among these considerations is not obvious and, like the other aspects in this section, remains an open research question.

\section{Future work}

As with any new method, the Diverse Voices has room for improvement as well as new aspects to explore. The section above on design trade-offs or limitations point to some. We bring forward other aspects here.

In this initial effort, we employed two criteria to prioritize stakeholder groups for panels, namely groups (1) potentially significant impacted by the technology and (2) unlikely to have formal representation in the policymaking process. Importantly, neither our method nor value sensitive design more generally prescribes a particular ethical approach or principles for panel selection. Different ethical principles may lead to different sets of panels which, in turn, may have significant effect on outcomes from the method. Studying the relationship between the criteria or ethical approach employed and the panels assembled would be an important next step. Of particular interest is how and in what ways the specific focus on underrepresented groups should be accounted for in determining which panels to prioritize.

We also raise the question of what sort of analysis and synthesis from the panels might be most effective. In the two cases reported here, within each case, separate panels were analyzed and synthesized independently. Future work might explore other strategies. For example, a meta-analysis across panels might yield important cross-cutting insights. Future work might also invite panelists to participate in the analysis and synthesis activity for their panel. These variations extend the scope and duration of engagement and would be a significant shift from the current practice where experiential experts share their insights to a third-party conducting the analysis and preparing the synthesis.

Currently, the Diverse Voices method is not well formulated to elicit the responses of underrepresented group members with varying cognitive and language capabilities. For example, a panel comprised of pre-adolescent children would require additional scaffolding to participate (e.g., drawing on co-design methods that employ toys, drawing materials and so forth, facilitators might ask youth to draw, show how they would use the technology, or share what concerns they might have). Similarly, other types of techniques will be necessary for very low literacy groups, multi-lingual groups, persons with dementia, and so forth.

The current work does not explicitly investigate panelists' affective experience and beliefs about the efficacy of the process. Future work could seek to understand panelists' sense of agency and authority, such as the degree to which they feel the freedom to share what is on their minds and their ability to influence the direction of the discussion.

While the case studies demonstrate that the Diverse Voices method is effective for surfacing ways to meaningfully improve tech policy documents, the uptake of those insights depends on the document author. In work conducted 
after this article was submitted, we were approached by the State of Washington's Access to Justice Committee to help them improve revisions to the Access to Justice Technology Principles from the perspectives of under-represented groups; these principles govern how the court systems in the state of Washington acquire and use technology. The Committee was actively soliciting assistance and open to revising the principles based on feedback. We ran Diverse Voices panels with formerly incarcerated, immigrants, rural communities, and legal professionals, which resulted in two new principles-human touch and language access-being added to the initial set, and a host of other substantive changes. This example points toward conditions that support uptake. Future work could investigate ways to incentivize or obligate authors to improve their documents in response to panelist feedback or, at a minimum, to provide a compelling rationale for why no modifications were made. Such efforts will need to take into account local culture and government regulation.

\section{Conclusion}

Tech policy works well, when it works for a broad range of constituents. Processes that-in their structure and practice-fail to account for the lived experience and perspectives of diverse groups run the risk of generating tech policy that perpetrates unjust exclusion. In turn, costly and lengthy legal and political battles often follow, battles that might have been avoided had the policy been written with a more inclusive sensibility. Historically, public engagement has been employed to mitigate these issues, however, such engagement typically occurs early in the policymaking process with the net result that insights garnered frequently have an inconclusive impact on the final policy documents. Previous work has also found that public engagement methods tend to reify a divide between legal and technical experts on the one hand, and laypeople on the other. It is into this set of concerns and considerations that we make two contributions: first we provide a proof-of-concept for how value sensitive design can be applied proactively to improve tech policy during the design and development phase, and second we contribute the Diverse Voices method. While value sensitive design makes a claim that policy is itself an artifact to be designed, how to address policy from a value sensitive design approach has not been explored to date in the literature. Our work represents an early effort to do so and demonstrates the viability of this approach. More generally, we believe that a design thinking approach may be fresh and beneficial in the policymaking context. While our work has been grounded in value sensitive design, design thinking is a rich and varied field and other design thinking approaches should be explored (c.f. Bjögvinsson et al. 2012; Louridas 1999).
We have positioned the Diverse Voices method to change the precise wording of tech policy documents, such that the impact of the process is reflected in the content of the document that circulates among policymakers. Moreover, in structure and in practice, our method reduces the divide among different actors by treating all three groups-technologists, policymakers, and laypeople-as experts, albeit of different types. While the case studies we report here are focused on emerging information and related technologies, we believe the method can be used with a wide range of technologies (e.g., nuclear power plant waste; wind turbine farms) to elicit valuable insights from underrepresented stakeholder groups in a resource efficient manner. We hope that a design thinking approach and the Diverse Voices method, in particular, will be appreciated within those parameters-as progress, not perfection.

Open Access This article is distributed under the terms of the Creative Commons Attribution 4.0 International License (http://creativeco mmons.org/licenses/by/4.0/), which permits unrestricted use, distribution, and reproduction in any medium, provided you give appropriate credit to the original author(s) and the source, provide a link to the Creative Commons license, and indicate if changes were made.

\section{References}

Abelson, J., Forest, P.-G., Eyles, J., Smith, P., Martin, E., Gauvin, F. P. (2003). Deliberations about deliberative methods: Issues in the design and evaluation of public participation processes. Social Science \& Medicine, 57(2), 239-251.

Bickerstaff, K., Lorenzoni, I., Jones, M., \& Pidgeon, N. (2010). Locating scientific citizenship: The institutional contexts and cultures of public engagement. Science, Technology, \& Human Values, 35(4), 474-500.

Bjögvinsson, E., Ehn, P., \& Hillgren, P.-A. (2012). Design things and design thinking: Contemporary participatory design challenges. Design Issues, 28(3), 101-116.

Bogner, A. (2012). The paradox of participation experiments. Science, Technology, \& Human Values, 37(5), 506-527.

Borning, A., Friedman, B., Davis, J., \& Lin, P. (2005). Informing public deliberation: Value sensitive design of indicators for a large-scale urban simulation. In ECSCW 2005 (pp. 449-468). Dordrecht: Springer.

Coyne, R. (2005). Wicked problems revisited. Design Studies, 26(1), $5-17$.

Cross, N. (1982). Designerly ways of knowing. Design Studies, 3(4), 221-227.

Davison, A., Barns, I., \& Schibeci, R. (1997). Problematic publics: A critical review of surveys of public attitudes to biotechnology. Science, Technology, \& Human Values, 22(3), 317-348.

Dryzek, J. S., Goodin, R. E., Tucker, A., \& Reber, B. (2009). Promethean elites encounter precautionary publics: The case of GM foods. Science, Technology, \& Human Values, 34(3), 263-288.

Frewer, L. J., Howard, C., \& Shepherd, R. (1998). Understanding public attitudes to technology. Journal of Risk Research, 1(3), 221-235.

Friedman, B., Hendry, D. G. (In press). Value sensitive design: Shaping being with technology. Cambridge, MA: The MIT Press. 
Friedman, B., Kahn, P. H. Jr., Borning, A., \& Huldtgren, A. (2013). Value sensitive design and information systems. In Early engagement and new technologies: Opening up the laboratory, pp 55-95. New York: Springer.

Fung, A. (2003). Survey article: Recipes for public spheres: Eight institutional design choices and their consequences. Journal of Political Philosophy, 11(3), 338-367.

Guston, D. H. (1999). Evaluating the first U.S. consensus conference: The impact of the citizens' panel on telecommunications and the future of democracy. Science, Technology, \& Human Values 24(4):451-482.

Haimson, O. L., \& Hoffmann, A. L. (2016). Constructing and enforcing 'authentic' identity online: Facebook, real names, and non-normative identities. First Monday. https://doi.org/10.5210/fm.v21i6 .6791

Harding, S. (1992). Rethinking standpoint epistemology: What is strong objectivity? The Centennial Review, 36(3), 437-470.

Hartsock, N. C. M. (2003). The feminist standpoint: Developing the ground for a specifically feminist historical materialism. In S. Harding \& M. B. Hintikka (Eds.) Discovering reality (pp. 283 310). Dordrecht: Springer (Synthese Library 161). https://doi. org/10.1007/978-94-010-0101-4_15

Herman, L. (2013). Policy papers and policy analysis. Stanford Law School. http://law.stanford.edu/wp-content/uploads/2015/04/Defin itions-of-White-PapersBriefing-Books-Memos-2.pdf.

Irwin, A., Jensen, T. E., \& Jones, K. E. (2013). The good, the bad and the perfect: Criticizing engagement practice. Social Studies of Science, 43(1), 118-135.

Jasanoff, S. (2003). Technologies of humility: Citizen participation in governing science. Minerva, 41(3), 223-244.

Kerr, A., Cunningham-Burley, S., \& Tutton, R. (2007). Shifting subject positions: Experts and lay people in public dialogue. Social Studies of Science, 37(3), 385-411.

Kurath, M., \& Gisler, P. (2009). Informing, involving or engaging? Science communication, in the ages of atom-, bio-and nanotechnology. Public Understanding of Science, 18(5), 559-573

Louridas, P. (1999). Design as bricolage: Anthropology meets design thinking. Design Studies, 20(6), 517-535.

National Urban Fellows. (2012). Diversity counts: Racial and ethnic diversity among public service leadership.

Nelson, H. G., \& Stolterman, E. (2012). The design way: Intentional change in an unpredictable world. Cambridge: MIT Press.

Nielsen, J. (1994). Heuristic evaluation. In J. Nielsen \& R. L. Mack (Eds.), Usability inspection methods (pp. 25-62). New York: Wiley.
Pitkin, H. F. (1967). The concept of representation. California: University of California Press.

Rettig, M. (1994). Prototyping for tiny fingers. Communications of the ACM, 37(4), 21-27.

Richert, M. (n.d.) We should not have to fight for the right to read. Public Knowledge. Accessed July 20, 2016.

Riker, W. H. (1986) The art of political manipulation, vol. 587. New Haven: Yale University Press

Rowe, G., \& Frewer, L. J. (2000). Public participation methods: A framework for evaluation. Science, Technology \& Human Values, 25(1), 3-29.

Sabatier, P. A., \& Weible, C. M. (Eds.) (2014). Theories of the policy process. Boulder: Westview Press.

Schlager, E. (1995). Policy making and collective action: Defining coalitions within the advocacy coalition framework. Policy Sciences, 28(3), 243-270.

Schön, D. A. (1987). Educating the reflective practitioner: Toward a new design for teaching and learning in the professions. San Francisco: Jossey-Bass.

Strategic Policy Making Team. (1999). Professional policy making for the 21st century. London: The Cabinet Office.

Sturgis, P., \& Allum, N. (2004). Science in society: Re-evaluating the deficit model of public attitudes. Public Understanding of Science, 13(1), 55-74.

Van den Hoven, J., Lokhorst, G.-J., \& Van de Poel, I. (2012). Engineering and the problem of moral overload. Science and Engineering Ethics, 18(1), 143-155. https://doi.org/10.1007/s1194 8-011-9277-z.

Voß, J.-P., \& Amelung, N. (2016). Innovating public participation methods: Technoscientization and reflexive engagement. Social Studies of Science, 46(5), 749-772.

Wynne, B. (2006). Public engagement as a means of restoring public trust in science-Hitting the notes, but missing the music? Public Health Genomics, 9(3), 211-220.

Yoo, D., Lake, M., Nilsen, T., Utter, M. E., Alsdorf, R., Bizimana, T., Nathan, L. P., et al. (2013). Envisioning across Generations: A multi-lifespan information system for international justice in Rwanda. In Proceedings of CHI2013, 2527-2536. ACM.

Publisher's Note Springer Nature remains neutral with regard to jurisdictional claims in published maps and institutional affiliations. 